\title{
PERANCANGAN MESIN UJI TARIK UNTUK SPESIMEN ALUMINIUM DENGAN KAPASITAS 5 TON
}

\author{
Engkos Koswara ${ }^{1}$, Haris Budiman ${ }^{2}$, Nandang ${ }^{3}$ \\ Teknik Mresin, Fakultas Teknik Universitas Majalengka \\ email : ekoswara.ek@gmail.com ${ }^{1}$, harisbudimans@yahoo.com ${ }^{2}$
}

\begin{abstract}
ABSTRAK
Salah satu hal yang menyebabkan kegagalan pada elemen sebuah mesin adalah kekuatan material. Kekuatan merupakan sifat yang dimiliki oleh setiap material. Kekuatan pada material dibagi menjadi dua bagian yaitu kekuatan tarik dan kekuatan mulur. Bagaimanakah sifat kekuatan ini diketahui? Apakah ada cara untuk mengetahuinya? Kekuatan material bisa diperoleh dari sebuah pengujian yang dikenal dengan nama uji tarik. Dari pengujian itu selain diperoleh benda kerja yang putus karena proses penarikan, juga dihasilkan sebuah kurva uji tarik. Kurva ini merupakan gambaran dari proses pembebanan pada benda kerja mulai dari awal penarikan hingga benda kerja itu putus. Dalam penelitian ini dikembangkan bagaimana mengolah besarnya pembebanan dan perubahan panjang yang terjadi pada benda kerja. Pembebanan dan perubahan panjang benda kerja inilah yang nantinya akan dikonversi ke dalam kurva uji tarik. Pada mesin uji tarik ini besarnya pembebanan (kekuatan tarik) maksimal yang direncanakan adalah sebesar 5 ton. Benda kerja ditentukan menurut standar ASTM dengan perbandingan $\left(\frac{L_{0}}{\sqrt{A_{0}}}\right)=4,5$ pelat dan $\left(\frac{L_{0}}{D_{0}}\right)=4$ untuk silinder.
\end{abstract}

Kata Kunci: Mesin Uji Tarik, Spesimen Aluminium

\section{PENDAHULUAN}

Uji tarik penting dilakukan di dalam bidang manufaktur karena dengan pengujian ini dapat diketahui beberapa sifat mekanik material. Sifat mekanik material perlu diketahui ketika dilakukan perancangan sebuah konstruksi mesin. Banyak cara yang dapat dilakukan untuk mengetahui sifat mekanik material. Salah satu cara yang dapat dilakukan untuk mengetahui sifat mekanik material yaitu dengan melakukan pengujian yang dikenal dengan nama pengujian tarik.

Pengujian tarik merupakan salah satu pengujian mekanik yang paling populer dibandingkan pengujian mekanik yang lainnya. Dari pengujian itu selain diperoleh benda kerja yang putus karena proses penarikan, juga dihasilkan sebuah kurva uji tarik. Kurva ini merupakan gambaran dari proses pembebanan pada benda kerja mulai dari awal penarikan hingga benda kerja itu putus. Dari kurva uji tarik ini dapat dihasilkan beberapa data-data sifat mekanik material. Adapun data yang dimaksud adalah kekuatan tarik (ultimate tensile strength), kekuatan mulur (yield strength atau yield point), elongasi (elongation), elastisitas (elasticity) dan pengurangan luas penampang (reduction of area). Data-data sifat mekanik material inilah yang nantinya akan digunakan dalam perancangan suatu elemen mesin.

Pengujian tarik banyak dilakukan di dunia industri ataupun di dunia pendidikan. Hanya saja kebanyakan kalangan pendidikan merasa keberatan untuk memiliki mesin uji tarik sendiri, karena mesin uji tarik yang ada dipasaran saat ini harganya relatif mahal. Harga mesin uji tarik yang telah dilengkapi dengan sistem perangkat pengolahan data biasanya jauh lebih mahal dibandingkan dengan mesin uji tarik konvensional. Pada umumnya mesin uji tarik yang dilengkapi dengan perangkat lunak banyak dipilih oleh penggunanya karena data yang diperoleh dapat dicatat dan diolah dengan mudah. Oleh karena itu, perlu dirancang mesin uji tarik yang murah namun dilengkapi dengan perangkat lunak sebagai pengolah datanya. 


\section{METODE PENELITIAN}

Secara umum proses perancangan mesin uji tarik merupakan perumusan rencana atau skema untuk membantu seorang dalam menciptakan produk. Dalam menciptakan sebuah produk tentunya seorang perancang banyak menemukan masalah dalam proses perancangan produk ini seperti pemilihan komponen yang akan digunakan, penentuan biaya produksi, dan penerapan metode dan alat yang digunakan.

Dalam proses perancangan diperlukan beberapa hal yang menunjang sebuah produk antara lain penelitian, konseptualisasi, penilaian kelayakan, penetapan persyaratan desain, perancangan awal, perancangan akhir, perencanaan produksi dan desain alat yang pada akhirnya menghasilkan produk yang diinginkan.

Alur penelitian perancangan mesin uji tarik dimulai dari perancangan mekanisme penarik, selanjutnya perancangan specimen alumunium, selanjutnya masuk ke perancangan ulir daya yaitu untuk proses naik atau turunnya batang penarik, setelah itu ada uji penarikan specimen, selanjutnya pemilihan untuk roda gigi, poros, bantalan, pasak dan kopling tetap.

\section{HASIL DAN PEBAHASAN}

1. Proses perancangan terdiri dari beberapa langkah. Adapun langkah-langkah yang dilakukan selama proses perancangan berlangsung adalah:

a. Mendefisikan perencanaan produk

b. Identifikasi pengguna dan kebutuhan mereka

c. Evaluasi produk sejenis

d. Spesifikasi teknik yang dihasilkan dan target yang ingin dicapai

e. Melakukan konseptualisasi desain

f. Melakukan evaluasi konsep

g. Mengembangkan produk atau prototipe

h. Evaluasi kinerja produk dan biaya

2. Spesifikasi mesin uji tarik berdasarkan hasil perancangan yaitu :

a. Mesin uji tarik yang dirancang dapat menghasilkan kekuatan tarik sebesar 5 ton $=49050 \mathrm{~N}$.

b. Spesimen berbentuk silinder dengan menggunakan standard ASTM $\left(\mathrm{L}_{0} \mathrm{D}_{0}=\right.$ 4).

c. Dimensi spesimen dibatasi berdasarkan kapsitas chuck dan panjang langkah penarikan maksimum mesin uji tarik yang dirancang. Dimensi spesimen harus memiliki spesifikasi diameter maksimum $\left(\mathrm{D}_{0 \text { maks }}\right)$ sebesar 16,3 $\mathrm{mm}$ dan panjang langkah penarikan maksimum $\left(\mathrm{L}_{\mathrm{fmaks}}\right)$ sebesar $160 \mathrm{~mm}$.

d. Mesin uji tarik yang dirancang memiliki dimensi panjang sebesar $840 \mathrm{~mm}$, lebar sebesar $500 \mathrm{~mm}$, dan tinggi sebesar 1100 $\mathrm{mm}$.

3. Komponen mesin uji tarik paling kritis terdapat pada bagian pasak roda gigi besar dengan FS = 1,08 pada gaya tarik maksimum.

4. Setelah dilakukan beberapa kali pengujian maka alat yang dibuat dapat dinyatakan aman.

\section{KESIMPULAN DAN SARAN \\ 4.1 Kesimpulan}

Setelah dilakukan perancangan konstruksi mesin uji tarik yang dilanjutkan dengan proses produksi mesin, maka dapat disimpulkan beberapa hal sebagai berikut :

1. Proses perancangan terdiri dari beberapa langkah. Adapun langkah-langkah yang dilakukan selama proses perancangan berlangsung adalah:

a. Mendefisikan perencanaan produk

b. Identifikasi pengguna dan kebutuhan mereka

c. Evaluasi produk sejenis

d. Spesifikasi teknik yang dihasilkan dan target yang ingin dicapai

e. Melakukan konseptualisasi desain

f. Melakukan evaluasi konsep

g. Mengembangkan produk atau prototipe

h. Evaluasi kinerja produk dan biaya

2. Spesifikasi mesin uji tarik berdasarkan hasil perancangan yaitu :

a. Mesin uji tarik yang dirancang dapat menghasilkan kekuatan tarik sebesar 5 ton $=49050 \mathrm{~N}$.

b. Spesimen berbentuk silinder dengan menggunakan standard ASTM $\left(\mathrm{L}_{0} \mathrm{D}_{0}=\right.$ 4).

c. Dimensi spesimen dibatasi berdasarkan kapsitas chuck dan panjang langkah penarikan maksimum mesin uji tarik yang dirancang. Dimensi spesimen harus memiliki spesifikasi diameter maksimum 
$\left(\mathrm{D}_{\text {Omaks }}\right)$ sebesar $16,3 \mathrm{~mm}$ dan panjang langkah penarikan maksimum $\left(\mathrm{L}_{\mathrm{fmaks}}\right)$ sebesar $160 \mathrm{~mm}$.

d. Mesin uji tarik yang dirancang memiliki dimensi panjang sebesar $840 \mathrm{~mm}$, lebar sebesar $500 \mathrm{~mm}$, dan tinggi sebesar 1100 $\mathrm{mm}$.

3. Komponen mesin uji tarik paling kritis terdapat pada bagian pasak roda gigi besar dengan $\mathrm{FS}=1,08$ pada gaya tarik maksimum.

4. Setelah dilakukan beberapa kali pengujian maka alat yang dibuat dapat dinyatakan aman.

5. Perkiraan biaya pembuatan mesin uji tarik mencapai angka Rp. 6.634.950,

\subsection{Saran}

Dalam perancangan konstruksi mesin uji tarik ini tentunya tidak terlepas dari beberapa kekurangan. Kekurangan itu terdapat pada desain konstruksi, perhitungan elemen-elemen mesin dan perancangan komponen-komponen yang digunakan sehingga perlu adanya beberapa perbaikan. Saran perbaikan yang dimaksud seperti:

a. Sebelum melakukan pemilihan komponen yang akan digunakan pada mekanisme alat sebaiknya perancang melakukan survey mengenai ketersediaan komponen dipasaran.

b. Perlu adanya interaksi aktif antara perancang dan pihak pembuat selama proses produksi berlangsung. Mengingat selalu ada perubahan dari rancangan yang harus disesuaiakan dengan kondisi di lapangan.

c. Pastikan komponen terpilih dapat bekerja dengan baik karena hal ini akan berdampak pada unjuk kerja mesin yang dibuat.

d. Perlu adanya modifikasi pada chuck untuk meningkatkan faktor keamanan dan kapasitas dimensi spesimen yang dapat diuji.

e. Pembuatan mesin dimaksudkan agar dapat mengamati fenomena proses pengujian tarik sehingga sangat disarankan menggunakan ulir daya yang memiliki jumlah kisar ulir satu.

\section{REFERENSI}

Anis, Samsudin. Buku ajar dasar pompa. Universitas negeri semarang: Semarang. 2008

Achdi, Endang. Panduan praktikum phenomena dasar mesin. Universitas tujuh belas agustus 1945 Cirebon: Cirebon. 2008

Hill, McGraw. fluid mechanics. Erlangga: Jakarta. 1985

Ir. Sularso, MSME, dasar perencanaan dan pemilihan elemen mesin

K. S. Y, Dua. Disain jaringan pipa. Mandar maju: Bandung. 2009

T.G. Hicks, T.W. Edwards. 1996. Teknologi Pemakaian Pompa. Erlangga: Jakarta

Sularso, Dasar Perencanaan Dan Pemilihan Elemen Mesin, 1987.

Achmad, Zainun. 1999. Elemen Mesin 1. Bandung: Refika Aditama.

Dieter, George. 1993. Metalurgi Mekanik Jilid 1. Jakarta: Erlangga.

Dieter, George. 1993. Metalurgi Mekanik Jilid 2. Jakarta: Erlangga.

E.P.POPOV.1995. Mekanika Teknik Jilid 2 Jakarta: Erlangga

Sonawan, Hery. 2010. Perancangan Elemen Mesin. Bandung: Alfabeta. 